\title{
Management of Chlamydia trachomatis genital tract infection: screening and treatment challenges
}

\author{
This article was published in the following Dove Press journal: \\ Infection and Drug Resistance \\ 19 January 2011 \\ Number of times this article has been viewed
}

\section{Brandie D Taylor \\ Catherine L Haggerty}

University of Pittsburgh, Department of Epidemiology, Pittsburgh, PA, USA

Correspondence: Brandie DePaoli Taylor University of Pittsburgh, Department of Epidemiology, 3602 Fifth Ave,

Pittsburgh, PA I52I3, USA

Tel + I 4I23025687

Fax + I 4I2383 II2I

Email depaolib@edc.pitt.edu
Abstract: Chlamydia trachomatis is a prevalent sexually transmitted infection that can lead to serious reproductive morbidity. Management and control of C. trachomatis is a challenge, largely due to its asymptomatic nature and our incomplete understanding of its natural history. Although chlamydia screening programs have been implemented worldwide, several countries have observed increasing rates of reported chlamydia cases. We reviewed the literature relating to the long-term complications of $C$. trachomatis, as well as screening strategies, treatment, and prevention strategies for reducing chlamydia in the population. Articles from 1950-2010 were identified through a Medline search using the keyword "Chlamydia trachomatis" combined with "screening", "pelvic inflammatory disease", "endometritis", "salpingitis", "infertility", “ectopic pregnancy”, “urethritis”, “epididymitis”, "proctitis”, “prostatitis”, "reinfection”, "cost-effectiveness", "treatment", "vaccines", or "prevention". Progression of C. trachomatis varies, and recurrent infections are common. Currently, there is limited evidence on the effectiveness of chlamydia screening. Higher quality studies are needed to determine the efficacy of more frequent screening, on a broader range of sequelae, including infertility and ectopic pregnancy, in addition to pelvic inflammatory disease. Studies should focus on delineating the natural history of recurrent infections, paying particular attention to treatment failures. Furthermore, alternatives to screening, such as vaccines, should continue to be explored.

Keywords: Chlamydia trachomatis, sexually transmitted disease, chlamydia screening, chlamydia treatment

\section{Introduction}

Chlamydia trachomatis genital tract infections are prevalent worldwide and can cause serious reproductive morbidity. ${ }^{1}$ In men, C. trachomatis is associated with nongonococcal urethritis and epididymitis. ${ }^{1-3}$ In women, chlamydia can lead to serious complications, including pelvic inflammatory disease (PID) and its subsequent sequelae, including ectopic pregnancy, infertility, and chronic pelvic pain. ${ }^{1,4-6}$ Chlamydial genital infections have also been reported to increase human immunodeficiency virus transmission and influence the development of human papilloma virus-induced adenocarcinoma. ${ }^{7,8}$ In addition, pregnant women infected with $C$. trachomatis put their children at risk for conjunctivitis and pneumonitis through mother to child transmission. ${ }^{9}$

The World Health Organization estimates that 92 million new cases of chlamydia occur worldwide every year. ${ }^{10}$ An estimated 3-4 million new cases occur every year in the US, 5 million in western Europe, and 16 million in Sub-Saharan Africa. ${ }^{10,11}$ Among men, chlamydia prevalence has been reported to be as high as $15 \%-20 \%$ in high-risk populations (such as those attending sexually transmitted disease clinics) and ranges 
from 3\%-7\% among asymptomatic populations. ${ }^{1,11,13-16}$ In women, chlamydia prevalence has been reported to range from $11.4 \%$ to greater than $20 \%$ in high-risk populations, and among asymptomatic patients has been reported to range from $3.0 \%$ in the general population to $9.5 \%$ among university students..$^{1,12,14-19}$ Due to the burden of chlamydia, the US Centers for Disease Control (CDC) recommends annual screening for all sexually active women younger than 26 years. ${ }^{20}$ Several countries have adopted similar screening programs or plan to implement programs that generally focus on identification and treatment, screening for asymptomatic infection, and partner notification. ${ }^{20-23}$

In parts of the US and in other countries, there has recently been an increase in reported chlamydia cases. ${ }^{20,22-30}$ In part, these increasing rates may be attributed to the implementation of new screening practices, reporting of chlamydia cases, improvement in diagnostics with increased sensitivity, changes in sexual behavior, or changes in natural immunity. One explanation for the rising rates is the "arrested development" hypothesis, where aggressive screening and treatment actually blunts natural immunity to chlamydial infection, increasing reinfection. ${ }^{26,30}$ The validity of this hypothesis continues to be debated. ${ }^{28-32}$ Still, the increase in reported chlamydia cases has raised concern about the effectiveness of current screening programs. This review will examine the current management and screening practices, as well as the challenges in the control of chlamydia genital tract infections.

\section{Methods}

Our primary literature search was conducted with Medline to identify randomized clinical trials, from 1950 through 2010, which examined the effectiveness of C. trachomatis screening in reducing reproductive morbidity. The term "Chlamydia trachomatis" was combined with "screening", "pelvic inflammatory disease", "endometritis", "salpingitis", "infertility", or "ectopic pregnancy". Citations were limited to human studies involving nonpregnant women. Postabortion and transcervical instrumentation studies were excluded. This search yielded three randomized clinical trials examining the effectiveness of chlamydia screening to reduce PID (see Table). The same key words, excluding "screening", were used to identify articles examining chlamydial complications in women. In a separate search, "Chlamydia trachomatis" and "reinfection" were combined with "pelvic inflammatory disease", "endometritis", "salpingitis", "infertility", or "ectopic pregnancy". A new search with keywords "Chlamydia trachomatis" and "urethritis", "epididymitis", "proctitis", or "prostatitis" was used to identify articles examining chlamydial complications in men. Other searches included the keywords "Chlamydia trachomatis" and "cost-effectiveness", "treatment", "vaccines", or "prevention". We also crossreferenced articles to identify additional references.

\section{Symptoms, complications, and long-term reproductive outcomes Chlamydial genital tract infections in men}

Chlamydial genital tract infections are asymptomatic in approximately $50 \%$ of men. ${ }^{33,34}$ If symptoms are present they are generally mild, ${ }^{35,36}$ compromising early identification, which may lead to nongonococcal urethritis. ${ }^{1-3,37-39}$ Urethral infection with $C$. trachomatis can ascend from the lower genital tract and cause inflammation of the epididymis, a structure on the back of the testicle where sperm is stored, a condition known as epididymitis. ${ }^{40-43}$ Approximately $45 \%-85 \%$ of men with epididymitis have had prior C. trachomatis infections and/or gonococcal infections. ${ }^{40,41,44}$ C. trachomatis is also associated with proctitis and inflammation of the rectal mucosa in both lymphogranuloma venereum (LGV, systemic C. trachomatis infection caused by serovars L1-L3), and non-LGV strains (genital infection caused by serovars B and D-K). ${ }^{1}$ Once rarely identified in industrialized nations, reports of LGV proctitis among men who have sex with men have recently been increasing throughout Europe, North America, and Australia. ${ }^{45}$ Because symptoms of LGV proctitis are nonspecific and unfamiliar to many physicians in industrialized countries, diagnosis may be delayed. ${ }^{45}$

Chlamydial infections may also cause prostatitis, although this relationship has not been completely delineated. C. trachomatis has been detected in up to $30 \%$ of prostatic or semen secretion samples and in $2.2 \%$ to $33 \%$ of prostate tissue samples collected from prostatitis patients. ${ }^{46-56}$ In contrast, a medical record-based retrospective cohort study of 17,764 US Air Force males did not find any significant associations between $C$. trachomatis and the development of prostatitis (hazard ratio [HR] 1.16, 95\% confidence interval [CI] 0.82-1.62). ${ }^{57}$ Furthermore, two studies using transperineal biopsy of the prostate, suggested to be the best method for reducing contamination from the lower genital tract, ${ }^{58}$ failed to isolate $C$. trachomatis from any of their biopsy patients. ${ }^{58,59}$ There are several possible reasons for the discrepant findings among these studies, including different study populations, varying definitions of prostatitis, and different C. trachomatis diagnostic methods. Furthermore, semen samples, prostatic secretions, and some prostate tissue 
Table Randomized trials examining the effectiveness of screening in preventing pelvic inflammatory disease in nonpregnant women

\begin{tabular}{|c|c|c|c|c|}
\hline Author/year & $\begin{array}{l}\text { Study } \\
\text { population }\end{array}$ & Methods & Randomization & Results \\
\hline Oakeshott et $\mathrm{al}^{92}$ & $\begin{array}{l}2529 \text { sexually } \\
\text { active female } \\
\text { students, aged } \\
16-27 \text { years, } \\
\text { recruited from } \\
20 \text { universities } \\
\text { in London, UK. }\end{array}$ & $\begin{array}{l}\text { Participants provided self-collected } \\
\text { vaginal samples at baseline and } \\
\text { completed a questionnaire on sexual } \\
\text { health. CT was diagnosed using TMA. } \\
\text { After one year, participants completed } \\
\text { a questionnaire about possible } \\
\text { symptoms of PID and sexual } \\
\text { behavior over the past year. } \\
\text { Medical records were } \\
\text { collected for I7\% and three doctors } \\
\text { blinded to study group and } \\
\text { CT status at baseline allocated } \\
\text { reported PID cases into } \\
\text { probable, possible, or no PID, } \\
\text { using the CDC guidelines and } \\
\text { Hager's criteria. }\end{array}$ & $\begin{array}{l}98.6 \%(2529 / 2563) \\
\text { were randomly } \\
\text { allocated for } \\
\text { immediate CT } \\
\text { screening and } \\
\text { treatment (I } 259) \\
\text { or deferred screening } \\
\text { (I I86; vaginal samples } \\
\text { analyzed after one year) } \\
\text { using random number } \\
\text { tables. } 94 \% \text { ( } 2377 / 2529) \\
\text { were followed up } \\
\text { after one year. }\end{array}$ & $\begin{array}{l}\text { Incidence of PID } \\
\text { was I.3\% (I5/II9I) } \\
\text { for screened group and } \\
\text { I.9\% }(23 / I \mid 86) \text { for } \\
\text { controls (RR 0.65, } \\
95 \% \mathrm{CI} 0.34-I .22) \text {. } \\
9.5 \% \text { ( } 7 / 74) \text { of CT } \\
\text { positive women at } \\
\text { baseline in control } \\
\text { group developed PID. } \\
\text { I.6\% (I/63) of CT } \\
\text { positive women in } \\
\text { screening group } \\
\text { developed PID } \\
\text { (RR 0.I7, } \\
95 \% \text { CI 0.03-I.0I). }\end{array}$ \\
\hline Østergaard et al ${ }^{121}$ & $\begin{array}{l}\text { I700 sexually } \\
\text { active female } \\
\text { high school } \\
\text { students from } \\
\text { Denmark, } \\
\text { aged } \geq 15 \text { years. }\end{array}$ & $\begin{array}{l}\text { Intervention group received a home } \\
\text { sampling kit at baseline and questionnaire. } \\
\text { Those who were CT-positive } \\
\text { (diagnosed by TMA) were referred } \\
\text { for treatment. The control group } \\
\text { received the same questionnaire } \\
\text { with an offer of free testing at a local } \\
\text { clinic or doctor's office. Home } \\
\text { sampling kits were sent at follow-up } \\
\text { to determine CT incidence. } \\
\text { Follow-up questionnaire collected } \\
\text { information on treatment or } \\
\text { hospitalization for PID during } \\
\text { the past year. Medical records were } \\
\text { sought through the central Danish } \\
\text { register for prescriptions related to PID. }\end{array}$ & $\begin{array}{l}5487 \text { female high } \\
\text { school students } \\
\text { were randomized }(I: I) \\
\text { by simple redeeming } \\
\text { to a home sampling } \\
\text { group ( } 2603) \text { or a usual } \\
\text { care group (2884). } \\
43 \% \text { ( } 235 \text { I/5487) } \\
\text { responded to the } \\
\text { baseline questionnaire. } \\
\text { Among sexually } \\
\text { active females } 55 \% \\
\text { (930/I700) were } \\
\text { followed for I year. }\end{array}$ & $\begin{array}{l}\text { Incidence of PID } \\
\text { was } 2.1 \% \text { in } \\
\text { the intervention } \\
\text { group and } 4.2 \% \\
\text { in the control } \\
\text { group }(P=0.045)\end{array}$ \\
\hline Scholes et $\mathrm{al}^{120}$ & $\begin{array}{l}2607 \text { sexually } \\
\text { active female } \\
\text { HMO enrollees } \\
\text { aged I8-34 years } \\
\text { from Washington } \\
\text { State, US. }\end{array}$ & $\begin{array}{l}\text { Self-administered questionnaires were } \\
\text { mailed to single HMO enrollees to } \\
\text { determine those at high risk of CT } \\
\text { (based on age, race, gravidity, and } \\
\text { sexual partner in the past I } 2 \text { months). } \\
\text { Emphasis was placed on contacting } \\
\text { nonresponders who were assigned to } \\
\text { the screening group. In the screening } \\
\text { group swabs were tested for CT by } \\
\text { ELISA. Specimens collected by cytobrush } \\
\text { were tested by chlamydia cell culture. } \\
\text { Control group (usual care) saw their } \\
\text { providers as needed. Both groups } \\
\text { received a follow-up questionnaire } \\
\text { at I } 2 \text { months and were asked about } \\
\text { diagnosis of PID. Outpatient and } \\
\text { inpatient databases were used to identify } \\
\text { those participants with a diagnosis of PID. } \\
\text { Medical records of those with possible } \\
\text { cases of PID were reviewed by blinded } \\
\text { abstracters to determine PID status } \\
\text { (based on signs, symptoms, and } \\
\text { laboratory findings). }\end{array}$ & $\begin{array}{l}57 \%(20,836 / 36,547) \\
\text { responded to the initial } \\
\text { questionnaire and } 85 \% \\
(17,725) \text { of responders } \\
\text { were ineligible. Of the } \\
\text { I3\% eligible ( } 2607) \text {, } \\
\text { I009 were randomly } \\
\text { assigned (authors did } \\
\text { not give randomization } \\
\text { method) to the } \\
\text { screening group and } \\
\text { I598 to the } \\
\text { usual care group. } 64 \% \\
\text { (645/I009) of women } \\
\text { in the screening group } \\
\text { were tested for CT. } \\
76 \% \text { were followed-up } \\
\text { at I } 2 \text { months. }\end{array}$ & $\begin{array}{l}\text { Databases identified } \\
57 \text { participants } \\
\text { diagnosed with PID. } \\
\text { Medical records } \\
\text { showed a clinical } \\
\text { diagnosis of PID in } \\
37 \text { participants. } \\
\text { Additional } 5 \text { were } \\
\text { identified in chart } \\
\text { review. } \\
9 \text { confirmed cases } \\
\text { of incident PID in the } \\
\text { screening group and } \\
33 \text { in the usual } \\
\text { care group (RR 0.44, } \\
95 \% \text { CI } 0.20-0.90 \text { ). }\end{array}$ \\
\hline
\end{tabular}

Abbreviations: CT, Chlamydia trachomatis; TMA, transcription mediated amplification; PID, pelvic inflammatory disease; CDC, Centers for Disease Control; RR, relative risk; $\mathrm{Cl}$, confidence interval; $\mathrm{HMO}$, health maintenance organization; ELISA, enzyme-linked immunosorbent assay. 
samples (such as transrectal biopsy or transurethral resection) can be contaminated by the lower genital tract, making it difficult to identify C. trachomatis directly in the prostate.

The debate over the role of $C$. trachomatis in male upper genital tract pathology has also raised questions about the impact of chlamydial infection on male fertility. Indeed, studies examining the relationship between $C$. trachomatis and male factor infertility have also been inconclusive, ${ }^{57,60-65}$ and few high quality prospective studies exist. Still, the risk of transmission to female partners leading to PID, ectopic pregnancy, or infertility ${ }^{1,4-6}$ is of great concern. Furthermore, reinfection rates in males have been reported to be approximately $11.3 \%$, which is similar to reinfection rates in women. ${ }^{66}$ Because reinfection in women may be associated with increased risk of reproductive morbidity, there is concern over the risk of transmission to female partners following repeated infections.

\section{Chlamydial genital tract infections in women}

Although $C$. trachomatis generally runs an asymptomatic course in approximately $80 \%$ of women, ${ }^{34}$ it is associated with serious reproductive morbidity. C. trachomatis can infect the columnar epithelial cells of the endocervix and cause cervicitis, ${ }^{1,67,68}$ and is also associated with urethritis. ${ }^{69,70}$ Although chlamydial cervicitis is often asymptomatic, it does cause mucopurulent discharge in about $37 \%$ of women and hypertrophic ectopy (an area of ectopy that is edematous and bleeds easily) in 19\% of women. ${ }^{1}$ However, there are no specific genital symptoms that are correlated with chlamydial infection of the cervix for diagnosis. ${ }^{1}$

Lower genital chlamydial infection can ascend to the upper genital tract, leading to serious complications. There are several ways $C$. trachomatis may be able to ascend into the upper genital tract. First, C. trachomatis has been shown in vitro to be able to attach to spermatozoa, ${ }^{71,72}$ possibly promoting rapid ascension into the upper genital tract. ${ }^{73}$ Second, the characteristics and production of the mucus plug, which is important for the protection against microorganisms, can be changed by hormonal fluctuations during the menstrual cycle, possibly influencing ascension. ${ }^{74}$ Hormone levels at menarche also increase cervical ectopy in young women, ${ }^{74}$ which provides a larger area for bacterial attachment. Lastly, subendometrial contractions, which are amplified prior to ovulation, may also promote ascension. ${ }^{75}$

C. trachomatis is a frequent pathogen of $\mathrm{PID},{ }^{76-78}$ and is isolated in the upper genital tract of about a quarter of PID patients. ${ }^{77,79,80}$ C. trachomatis has been found to be associated with both endometritis ${ }^{81,82}$ as well as laparoscopically confirmed salpingitis. ${ }^{77,83-85}$ However, rates of progression vary widely between patients. Among untreated $C$. trachomatis-positive women, studies have reported that $2.0 \%-4.5 \%$ developed clinical PID within approximately 14 days. ${ }^{86-88}$ However, studies with longer follow-up have reported lower rates of PID following untreated chlamydial infection, ranging from $0 \%-9.5 \%{ }^{89-92}$ In the largest study, conducted in Norway between 1990 and 2005, 1.09\% (48/4413) of women who tested positive for $C$. trachomatis were hospitalized for PID. ${ }^{91}$ However, several methods for chlamydia testing were used throughout the study period. Furthermore, severe PID resulting in hospitalization represents a small proportion of PID cases. ${ }^{74}$ Because most cases of PID are mild to moderate and treated as outpatients, this study likely represents an underestimation of chlamydia-associated PID. In the randomized controlled Prevention Of Pelvic Infection (POPI) trial, 9.5\% (7/74) of untreated chlamydia-positive women (determined by nucleic acid amplification test) developed clinical PID within 12 months of follow-up. ${ }^{92}$ However, only $17 \%$ of self-reported PID cases were verified by medical records. In a prospective study of 1170 women from five US sites, $19 \%(23 / 122)$ of those with treated chlamydial infection at baseline (nucleic acid amplification test) developed clinical PID within three years of follow-up. ${ }^{93}$

Actual rates of progression of chlamydial infection to reproductive sequelae are unknown. Studies have found associations with prior chlamydial infections and tubal factor infertility, ${ }^{94-97}$ as well as ectopic pregnancy. ${ }^{5,98,99}$ However, very few prospective studies have examined infertility following chlamydial PID. Haggerty et al reported that, among a cohort of women with clinically suspected PID, sequelae following chlamydial upper genital tract infection was high (19.0\% infertility, $15.0 \%$ recurrent PID, $20.7 \%$ chronic pelvic pain), although no significant associations were found.$^{80}$ It is possible that women in this cohort could have had prior chlamydial infections that resulted in tubal damage preceding the PID episode, resulting in bias towards the null. Brunham et al found that seven of 13 women with nongonococcal infection had an adverse reproductive outcome, compared with none of 10 women with gonococcal infection $(P=0.007) .{ }^{4}$ Of the seven infertile women, three had evidence of chlamydial infection. A retrospective study of 51 women with PID found that those who were culture-positive for $C$. trachomatis were more likely to experience involuntary infertility compared with those who tested negative for chlamydia (relative risk [RR] 2.5, 95\% CI 1.0-6.2). ${ }^{100}$ Because rates of progression 
vary widely between individuals, it is imperative that studies strive to understand further the natural history and pathogenesis of $C$. trachomatis. This will improve treatment and control measures, and aid in vaccine development.

Repeated chlamydial infections are common ${ }^{101,102}$ and may increase the risk of sequelae. ${ }^{102-104}$ In a study of 11,000 women aged 10 -44 years, those who had $\geq$ three chlamydial infections, determined by nucleic acid amplification test, were six times more likely to be diagnosed with PID (odds ratio [OR] 6.4, 95\% CI 2.2-18.4). ${ }^{102}$ Furthermore, those with two infections and $\geq$ three infections were two times (OR 2.1, 95\% CI 1.3-3.4) and four times (OR 4.5, 95\% CI 1.8-5.3) more likely to have an ectopic pregnancy. ${ }^{102}$ Similarly, a prospective study among 302 female sex workers in Nairobi, Kenya, reported that repeated $C$. trachomatis infection was associated with a cumulative risk of PID over 18 months (OR 1.8, 95\% CI 1.3-2.4). ${ }^{103}$ Lastly, Ness et al reported that in 443 women with clinically suspected PID, recurrence was higher (HR 2.48, 95\% CI 1.00-6.27) and pregnancy rates were significantly lower (HR 0.47, 95\% CI 0.28-0.79) among women whose antibody titers to chlamydia elementary bodies were in the highest tertile. ${ }^{104}$

Determining the risk of sequelae following repeated chlamydial infections is difficult because the duration of infection is generally unknown. Furthermore, ascertainment bias may be present, because physicians who are aware of previous infections may be more inclined to diagnose pelvic pain as clinically suspected PID. Still, studies generally suggest that repeated chlamydial infections may increase the risk of sequelae. It is important to determine the epidemiology of repeated infections, particularly if they are caused by treatment failures, increased susceptibility to infection due to host immunity, or reinfection from an untreated partner.

\section{Screening}

Routine screening for C. trachomatis has been implemented worldwide, with the goal of interrupting progression or reducing transmission to prevent long-term morbidity. However, there is no single accepted screening strategy that has been consistently implemented. Many screening programs target young women under the age of 26 years, focusing on identification and treatment, screening for asymptomatic infection, and partner notification. ${ }^{20-23}$ Recommendations for screening men varies, but should be evaluated because screening both men and women may more adequately reduce transmission. ${ }^{22}$ Frequency of screening also varies between programs. The US and the UK often use opportunistic screening approaches whereby physicians offer chlamydia screening to young women when they attend health care or similar settings for unrelated reasons. ${ }^{105}$ Retesting is generally the responsibility of the physician. Register-based (proactive) screening, used in some parts of The Netherlands, utilizes a register of the target population and sends invitations for screening (invitations are resent to nonresponders) to ensure that a high proportion of the target population is reached at adequate intervals. ${ }^{105}$ It is important that countries evaluate their screening rates in the population. A high proportion of the target population should be reached to ensure that regular screening and partner notification are achieved to reduce morbidity significantly.

In selected populations, such as sexually active adolescents and young women, chlamydia screening is suggested to be cost-effective. ${ }^{106-109}$ However, there is little evidence that chlamydia screening is cost-effective in other populations or in males. Furthermore, cost-effectiveness is suggested to be influenced by the rate of complications, ${ }^{110-112}$ which may be lower than previously estimated. ${ }^{111,112}$ In fact, two studies using a dynamic simulation model reported that when complication rates are low, chlamydia screening may not be cost-effective. ${ }^{113,114}$ These findings suggests that better estimates of morbidity risk are needed to evaluate screening programs fully. ${ }^{112}$ However, because the natural history of C. trachomatis has not been completely delineated, estimating these risks may be difficult.

Despite screening programs, many countries, such as the US, Sweden, and Canada, have recently seen rising rates of chlamydia cases. ${ }^{20,22-30}$ For example, in 2008, 1.2 million cases of chlamydia were reported to the US CDC, ie, a 9.2\% increase from 2007 and the largest number of cases ever reported to the US CDC for any disease. ${ }^{20}$ Estimates based on case reports need to be interpreted with caution because they do not truly reflect prevalence or incidence of chlamydial infections. However, $C$. trachomatis is still very much underreported due to its asymptomatic nature, and the increased rates may not be artificial. ${ }^{28,30}$ For example, there may be a true increase in incidence, which could ultimately lead to an increase in chronic untreated asymptomatic infection, thus leading to a higher prevalence.

There are several possible explanations for the rising rates. For example, the switch to more sensitive tests, such as nucleic acid amplification testing, introduced in the 1990s, which can be performed on both urine and female self-collection swabs, may contribute to the increase in chlamydial rates. However, Gotz et al report that, in Sweden between 1991 and 1999, increases in chlamydia were reported in both laboratories that changed to more sensitive methods 
and those that did not, ${ }^{28}$ suggesting that changes in diagnostics did not completely account for the increasing rates in Sweden. ${ }^{28}$ Collection by urine or female self-collection swabs is an advantage over other testing methods which rely on urethral and endocervical swabs. Self-collection swabs may be mailed directly from home to a laboratory. Because these methods may be more acceptable to people, testing rates may have increased as a result. For example, a study out of Denmark reported that home-sampling increased the number of women tested by 11 -fold compared with sampling at a doctor's office. ${ }^{115}$

There are several other hypotheses that may explain the increasing chlamydia rates including changes in sexual behavior, increases in chlamydia reporting, changes in treatment failure, failure to achieve adequate partner notification, and changes in natural immunity. In the early 1990s in countries without screening programs, reduced chlamydia rates coincided with human immunodeficiency virus prevention campaigns. ${ }^{105,116}$ This may suggest that an increase in condom use and abstinence could have accounted for the decreasing rates, and increases in risky sexual behavior could influence rates today. Other hypotheses also exist. The "arrested development" hypothesis suggests that aggressive early treatment blunts the natural immune response to chlamydial infection, essentially increasing the rate of chlamydial reinfection. ${ }^{26,30}$ Studies have shown that there is an increase in repeated chlamydial infections following treatment. ${ }^{117-119}$ In addition, Brunham et al reported that despite changes in diagnostics at different times, $C$. trachomatis reinfection has increased $4.6 \%$ per year in British Columbia since $1989 .{ }^{26} \mathrm{It}$ is possible that women who are screened are in general at higher risk for sexually transmitted infections, and thus are more likely to have reinfection independent of screening and treatment. Still, studies should continue to evaluate the role of host immunity in both the course and outcome of chlamydial infections, as well as compare immunity, duration, and risks of complications in initial and repeated infections. If repeated infections truly cause more sequelae than initial infections, then more frequent screening or screening focused on repeated infections should be evaluated. There is also a need for better estimates of chlamydia incidence. Indeed, if the observed increases in chlamydia cases do reflect a true increase in chlamydia incidence, then current screening strategies may not be efficient in reducing transmission.

Low et al argue that the evidence examining the effectiveness of chlamydia screening is limited, because very few randomized clinical trials exist. ${ }^{105}$ Furthermore, there are no randomized trials that have examined complications, such as infertility or ectopic pregnancies. One randomized trial of 2607 high-risk women recruited from a Seattle health maintenance organization found that one-time screening significantly reduced the risk of clinical PID (RR 0.44, 95\% CI 0.20-0.90) within one year of follow-up (see Table). ${ }^{20}$ Nonresponders in the intervention group were aggressively contacted, which may have resulted in selection bias. ${ }^{120}$ In addition, only $64 \%$ of the screening group actually attended a study clinic for chlamydia testing, and $24 \%$ were lost to follow-up. In a cluster randomized trial among male and female high school students, Østergaard et al reported that one-time screening significantly reduced PID (based on self-reported treatment and hospitalization for PID) within one year when home sampling was compared with usual care $(4.2 \%$ versus $2.1 \%, P=0.045) .{ }^{121}$ The usual care group was offered free screening at a local clinic or doctor's office, although only 63 of 833 females in the control group were reported to be tested for chlamydia. However, this trial was not blinded and approximately $45 \%$ were lost to follow-up. Furthermore, because chlamydia is not the only cause of PID, the estimated effect of screening on PID incidence has been suggested to be overestimated in both studies. ${ }^{92,105}$ In another randomized trial (POPI), there was a limited impact of annual $C$. trachomatis screening on self-reported clinically suspected PID incidence (RR 0.65, 95\% CI 0.34-1.22) between women who were screened $(1.3 \%, 15 / 1191)$ and controls $(1.9 \%, 23 / 1186) .{ }^{92}$ However, the incidence of PID was only $1.9 \%$, which was lower than the estimated $3 \%$ used to power the study.

When evaluating the effectiveness of screening programs to reduce reproductive morbidity, there are several possible limitations in using PID as an outcome. First, several other microorganisms have been implicated in the etiology of PID, making it difficult to determine the proportion of PID cases specifically attributed to $C$. trachomatis. Second, signs and symptoms of PID vary widely, thus diagnosis of clinically suspected PID is nonspecific. Lastly, C. trachomatis has been found to increase the odds of subclinical PID six-fold (OR 6.1, 95\% CI 1.8-2.1), ${ }^{122}$ suggesting that increases in C. trachomatis upper genital tract infection may increase subclinical PID in the population. Women with subclinical PID have very mild or no symptoms,${ }^{74}$ and PID may go undiagnosed in many women with chlamydial infection. Thus, the effectiveness of screening programs to reduce other reproductive sequelae should be explored. However, infertility can also be difficult to diagnose, because it can take years to develop and has several different causes. In addition, infertility can only be measured in women actively 
trying to conceive or those who rarely or never use reliable contraceptive methods. This same issue applies to ectopic pregnancy. Therefore, improved diagnostic methods for postchlamydial complications with high sensitivity and specificity are needed.

\section{Treatment and prevention}

Treatment of $C$. trachomatis infection is considered to be effective in preventing transmission to sexual partners. ${ }^{123}$ Several drugs are active against $C$. trachomatis in tissue cultures, including rifampin, tetracyclines, macrolides, sulfonamides, some fluoroquinolones, and clindamycin. ${ }^{1}$ Rifampin is highly active in vitro, but resistance to this drug can be readily developed. ${ }^{124}$ Thus, rifampin is not used to treat human chlamydial infections. ${ }^{1} \mathrm{C}$. trachomatis is also susceptible to sulfonamides, but they are not used for genital chlamydial infections. ${ }^{125}$ Currently, the US CDC recommends treatment with azithromycin ( $1 \mathrm{~g}$, single dose taken orally) or doxycycline (100 mg, twice per day for seven days). ${ }^{123}$ A recent meta-analysis revealed similar microbiological cure rates for azithromycin (97\%) and doxycycline (98\%). ${ }^{126}$ Azithromycin is recommended when compliance may be an issue, such as in adolescents or those with low socioeconomic status due to its ability to be given in a single dose. Alternative regimens can include erythromycin base (500 mg four times per day for seven days), erythromycin ethylsuccinate (800 $\mathrm{mg}$ four times per day for seven days), ofloxacin (300 mg twice a day for seven days), or levofloxacin (500 mg daily for seven days). ${ }^{123}$ Erythromycin is effective in treating chlamydia, but has side effects, which may reduce compliance. ${ }^{123}$ Levofloxacin and ofloxacin are also effective, but are expensive. ${ }^{123}$ There is currently no solid evidence of any in vivo antibiotic resistance for $C$. trachomatis genital tract infection. ${ }^{1,30,125}$ However, very few laboratories actually monitor chlamydial antibiotic resistance. ${ }^{30}$ Although recurrent infections are common in both men and women, it is unclear if they are due to treatment failures. In the US, it is likely that many treatment failures go unnoticed in asymptomatic infection, because test-of-cure (repeat testing three to four weeks after completing therapy) is not recommended, except in pregnant women. ${ }^{123}$

\section{Vaccines}

The asymptomatic nature of chlamydia makes diagnosis, treatment, and prevention of sequelae a challenge. Host immunity induced by chlamydial infections is not longlasting, and may take several months or years to develop. ${ }^{125}$ Further, a single C. trachomatis infection does not adequately protect against reinfection. ${ }^{125}$ In addition, it is hypothesized that aggressive treatment may blunt natural immunity. ${ }^{26,30}$ Therefore, control and management of chlamydia may depend on a safe and effective vaccine that can induce a better immune response than what occurs naturally. ${ }^{125}$ However, the pathogenesis of $C$. trachomatis has not been completely elucidated, and the role of host immunology is unclear. Coupled with a lack of a suitable animal model and inability to manipulate chlamydia genetically, researchers have yet to develop a successful vaccine.

Chlamydial surface antigens are possible vaccine candidates. ${ }^{125}$ Several chlamydial vaccine trials have used the major outer membrane protein as a vaccine candidate. However, studies using the major outer membrane protein have been inconclusive and immunity is generally shortlived. ${ }^{127-131}$ Furthermore, the major outer membrane protein is not serovar-specific. Thus, other antigens are currently being considered as vaccine candidates. The recently discovered surface-exposed protein, polymorphic membrane protein $\mathrm{D}$, has been shown to act as an adhesion molecule ${ }^{132}$ and can stimulate proinflammatory cytokines through the nuclear factor- $\mathrm{B}$ pathway. ${ }^{133}$ Crane et al found that polymorphic membrane protein can recruit host antibodies to the site of infection, making this protein a promising vaccine candidate. ${ }^{134}$ Antibody response was also neutralizing across different serovars. However, chlamydia may undergo a type of antigenic variation. ${ }^{135}$ Thus, it has been suggested that a single antigen may not be optimal as a vaccine candidate. Further increasing our knowledge of chlamydial pathogenesis will bring researchers closer to developing a successful vaccine.

\section{Conclusion}

There are several factors which may hinder the implementation of a successful chlamydia screening program. First, the evidence examining the effectiveness of chlamydia screening is limited, because few high quality randomized clinical trials exist. Furthermore, chlamydia screening strategies vary widely, and there is no evidence to suggest which screening strategy would best reduce reproductive morbidity. Second, cost-effective analyses, which are mainly conducted in young women, may be inaccurate because complication risks are lower than previously estimated. In fact, two studies using dynamic simulation models have suggested that chlamydia screening is not cost-effective when based on lower complication rates. Lastly, the high rate of repeated infections in the population and our incomplete understanding of the natural history of $C$. trachomatis have greatly challenged 
control efforts. Because the natural history of $C$. trachomatis has not been completely elucidated, it is unclear if screening can successfully interrupt progression before tubal damage and/or reduce transmission in the population.

It is clear that future research is needed to determine the best approach for chlamydia management. While it is difficult to assess screening programs, it would be optimal if the efficacy of more frequent $C$. trachomatis screening on a broader range of sequelae were explored, including infertility and ectopic pregnancy in addition to PID. Due to the previously mentioned limitations of using these outcomes to evaluate screening programs, improved diagnostic methods for chlamydial complications are needed. Alternatively, better estimates of chlamydia incidence can be used to determine if screening can efficiently reduce transmission. Because studies evaluating chlamydia screening have largely been conducted in women, future investigations should also focus on men. This is of particular importance because $C$. trachomatis is asymptomatic in half of men, leaving a high likelihood of transmission to sexual partners. It is imperative that the natural history and epidemiology of C. trachomatis continues to be explored in both single and repeated infections. Research should continue to explore host immunology, bacterial antigens, duration, and the role of pathogen load in the course and outcome of chlamydial infections. In addition, it is particularly important that future studies determine if repeated infections are caused by treatment failure. As chlamydia research progresses, current screening programs need to be evaluated carefully and other alternatives to screening, such as vaccine development, should continue to be explored.

\section{Disclosure}

The authors report no conflicts of interest in this work.

\section{References}

1. Stamm W. Chlamydia trachomatis infections of the adult. In: Homes K, Sparling P, Mardh P-A, et al, editors. Sexually Transmitted Diseases. New York, NY: McGraw Hill; 2008.

2. Holmes K, Handsfield H, Wang S, et al. Etiology of nongonococcal urethritis. N Engl J Med. 1975;292(23):1199-1205.

3. Oriel J, Reeve P, Powis P, Miller A, Nicol C. Chlamydia infection: Isolation of chlamydia from patients with non-specific genital infection. Br J Vener Dis. 1972;48(6):929-936.

4. Brunham R, Binns B, Guijon F, et al. Etiology and outcome of acute pelvic inflammatory disease. J Infect Dis. 1988;158(3):510-517.

5. Chow J, Yonekura M, Richwald G, et al. The association between Chlamydia trachomatis and ectopic pregnancy: A matched-pair, case-control study. JAMA. 1990;263(23):3164-3167.

6. Westrom L, Joesoef R, Reynolds G, Hagdu A, Thompson S. Pelvic inflammatory disease and fertility: A cohort of 1,844 women with laparoscopically verified disease and 657 control women with normal laparoscopic results. Sex Transm Dis. 1992;19(4):185-192.
7. Plummer F, Simonsen J, Cameron D, et al. Cofactors in male-female sexual transmission of human immunodeficiency virus type 1. J Infect Dis. 1991;163(2):233-239.

8. Madeleine M, Anttila T, Schwartz S, et al. Risk of cervical cancer associated with Chlamydia trachomatis antibodies by histology, HPV type and HPV cofactors. Int J Cancer. 2007;120(3):650-655.

9. Brocklehurst P, Rooney G. Interventions for treating genital Chlamydia trachomatis infection in pregnancy (review). Cochrane Database Syst Rev. 2000;2:CD000054.

10. World Health Organization. Global prevalence and incidence of selected curable sexually transmitted infections: Overview and estimates. Available from: http://whqlibdoc.who.int/hq/2001/WHO_HIV_ AIDS_2001.02.pdf. Accessed Jul 15, 2010.

11. Weinstock H, Berman S, Cates W Jr. Sexually transmitted diseases among American youth: Incidence and prevalence estimates, 2000. Perspect Sex Reprod Health. 2004;36(1):6-10.

12. Patel A, Rashid S, Godfrey E, Panchal H. Prevalence of Chlamydia trachomatis and Neisseria gonorrhoeae genital infections in a publicly funded pregnancy termination clinic: Empiric vs. indicated treatment? Contraception. 2008;78(4):328-331.

13. Schachter J, Hanna L, Hill EC, et al. Are chlamydial infections the most prevalent venereal disease? JAMA. 1974;57(12):1252-1255.

14. Imai $H$, Nakao $H$, Shinohara $H$, et al. Population-based study of asymptomatic infection with Chlamydia trachomatis among female and male students. Int J STD AIDS. 2010;21(5):362-366.

15. Satterwhite C, Tian L, Braxton J, Weinstock H. Chlamydia prevalence among women and men entering the National Job Training Program: United States, 2003-2007. Sex Transm Dis. 2010;37(2):63-74.

16. Quinn T, Gaydos C, Shepherd M, et al. Epidemiologic and microbiologic correlates of Chlamydia trachomatis infection in sexual partners. JAMA. 1996;476(21):1737-1742.

17. Forhan S, Gottlieb S, Sternberg M, et al. Prevalence of sexually transmitted infections among female adolescents aged 14 to 19 in the United States. Pediatrics. 2009;124(6):1505-1512.

18. Turner C, Rogers S, Miller H, et al. Untreated gonococcal and chlamydial infection in a probability sample of adults. JAMA. 2002; 287(6):726-733.

19. Miller W, Ford C, Morris M, et al. Prevalence of chlamydial and gonococcal infections among young adults in the United States. JAMA. 2004;291(18):2229-2236.

20. Centers for Disease Control and Prevention. Sexually Transmitted Disease Surveillance 2008. Atlanta, GA: US Department of Health and Human Services; 2009.

21. European Centre for Disease Prevention and Control. Chlamydia control in Europe. Stockholm, 2009. Available from: http://www.ecdc. europa.eu/en/publications/Publications/0906_GUI_Chlamydia_Con trol_in_Europe.pdf. Accessed Jul 20, 2010.

22. Hocking J, Walker J, Regan D, Chen M, Fairley C. Chlamydia screening - Australia should strive to achieve what others have not. Med J Aust. 2008;188(2)106-108.

23. Health Protection Agency. Sexually transmitted infections and young People in the United Kingdom: 2008 Report. 2008 Jul. Available from: http://www.hpa.org.uk/hpr/archives/2009/news2909.htm. Accessed Dec 18, 2010.

24. Fenton K, Lowndes C. Recent trends in the epidemiology of sexually transmitted infections in the European Union. Sex Transm Infect. 2004; 80(4):255-263.

25. Public Health Agency of Canada. Brief report on sexually transmitted infections in Canada: 2007. Available from: http:/www.phac-aspc.gc.ca/ publicat/2009/sti-its/pdf/sti_brief-its_bref_2009-eng.pdf. Accessed Jul 22, 2010 .

26. Brunham R, Pourbohloul B, Mak S, White R, Rekart M. The unexpected impact of a Chlamydia trachomatis infection control program on susceptibility to reinfection. J Infect Dis. 2005;192(10): 1836-1844.

27. Low N. Screening programs for chlamydial infection: When will we ever learn? BMJ. 2007;334(7596):725-728. 
28. Gotz H, Lindback J, Ripa T, Arneborn M, Ramstedt K, Ekdahl K. Is the increase in notifications of Chlamydia trachomatis infections in Sweden the result of changes in prevalence, sampling frequency or diagnostic methods? Scand J Infect Dis. 2002;34(1):28-34.

29. Vickers D, Osgood N. Current crisis of artifact of surveillance: Insights into rebound chlamydia rates from dynamic modeling. BMC Infect Dis. 2010;10:70.

30. Rekart M, Brunham R. Epidemiology of chlamydial infection: Are we losing ground? Sex Transm Infect. 2008:84(2):87-91.

31. Low N. Caution: Chlamydia surveillance data ahead. Sex Transm Infect. 2008;84(2):80-81.

32. Moss N, Ahrens K, Kent C, Klausner J. The decline in clinical sequelae of genital Chlamydia trachomatis infection supports current control strategies. J Infect Dis. 2006;193(9):1336-1338.

33. Karam G, Martin D, Flotte T, et al. Asymptomatic Chlamydia trachomatis infections among sexually active men. J Infect Dis. 1986; 154(5):900-903.

34. Zimmerman H, Potterat J, Dukes R, et al. Epidemiologic differences between chlamydia and gonorrhea. Am J Public Health. 1990;80(11): 1338-1342.

35. Stamm W, Koutsky L, Benedetti J, Jourden J, Brunham R, Holmes K Chlamydia trachomatis urethral infections in men. Prevalence, risk factors, and clinical manifestations. Ann Intern Med. 1984;100(1): 47-51.

36. Takahashi S, Takeyama K, Kunishima Y, et al. Analysis of clinical manifestations of male patients with urethritis. J Infect Chemother. 2006;12(5):286-286.

37. Yu J, Tang W, Lau K, Chong L, Lo K. Asymptomatic urethral infection in male sexually transmitted disease clinic attendees. Int J STD AIDS 2008;19(3):155-158.

38. Gaydos C, Maldeis N, Hardick A, Hardick J, Quinn T. Mycoplasma genitalium compared to chlamydia, gonorrhea and trichomonas as an aetiological agent of urethritis in men attending STD clinics. Sex Transm Infect. 2009;83(6):438-440.

39. Bradshaw C, Tabrizi S, Read T, et al. Etiologies of nongonococcal urethritis: Bacteria, viruses, and the association with orogenital exposure. J Infect Dis. 2006;193(3):336-345.

40. Berger R, Alexander E, Monda G, Ansell J, McCormick G, Holmes K Chlamydia trachomatis as a cause of acute "idiopathic" epididymitis. N Engl J Med. 1978;298(6):301-304.

41. Berger R, Alexander E, Harnisch J, et al. Etiology, manifestations and therapy of acute epididymitis: Prospective study of 50 cases. J Urol. 1979;121(6):750-754.

42. Redfern T, English P, Baumber C, McGhie D. The aetiology and management of acute epididymitis. Br J Surg. 1984;71(9):703-705.

43. Trojian T, Lishnak T, Heiman D. Epididymitis and orchitis: An overview. Am Fam Physician. 2009;79(7):583-587.

44. Melekos M, Asbach H. The role of chlamydiae in epididymitis. Int Urol Nephrol. 1988;20(3):293-297.

45. Martin-Iguacel R, Llibre J, Nielsen H, et al. Lymphogranuloma venereum proctocolitis: A silent endemic disease in men who have sex with men in industrialised countries. Eur J Clin Microbiol Infect Dis. 2010;29(8):917-925.

46. Badalyan R, Fanarjyan S, Aghajanyan I. Chlamydial and ureaplasmal infections in patients with nonbacterial chronic prostatitis. Andrologia. 2003;35(5):263-265

47. Motrich R, Cuffini C, Oberti J, Maccioni M, Rivero V. Chlamydia trachomatis occurrence and its impact on sperm quality in chronic prostatitis patients. $J$ Infect. 2006;53(3):175-183.

48. Zdrodwska-Stefanow B, Ostaszewska-Puchalska I, Badyda J, Galewska Z. The evaluation of markers of prostatic inflammation and function of the prostate gland in patients with chronic prostatitits. Arch Immunol Ther Exp. 2008;56(4):277-282.

49. Zdrodwska-Stefanow B, Ostaszewska-Puchalska I, Badyda J, Galewska Z. The effect of Chlamydia trachomatis infection of the prostate gland on the concentration of citric acid. Arch Immunol Ther Exp. 2006;54(1):69-73.
50. Ouzounova-Raykova V, Ouzounova I, Mitov I. May Chlamydia trachomatis be an aetiological agent of chronic prostatic infection? Andrologia. 2010;42(3):176-181.

51. Poletti F, Medici M, Alinovi A, et al. Isolation of Chlamydia trachomatis from the prostatic cells in patients affected by nonacute abacterial prostatitis. J Urol. 1985;134(4):691-693.

52. Shurbaji M, Gupta P, Myers J. Immunohistochemical demonstration of Chlamydia antigens in association with prostatitis. Mod Pathol. 1988;1(5):348-351.

53. Abdelatif O, Chandler F, McGuire B. Chlamydia trachomatis in chronic abacterial prostatitis: Demonstration by colorimetric in situ hybridization. Hum Pathol. 1991;22(1):41-44.

54. Corradi G, Bucsek M, Panovics J, et al. Detection of Chlamydia trachomatis in the prostate by in-situ hybridization and by transmission electron microscopy. Int J Androl. 1996;19(2):109-112.

55. Weidner W, Diemer T, Huwe P, Rainer H, Ludwig M. The role of Chlamydia trachomatis in prostatitis. Int J Antimicrob Agents. 2002; 19(6):466-470.

56. Kreiger J, Riley D. Chronic prostatitis: Charlottesville to Seattle. J Urol. 2004;172(6 Pt 2):2557-2560.

57. Trei J, Canas L, Gould P. Reproductive tract complications associated with Chlamydia trachomatis infection in US Air Force Males within 4 years of testing. Sex Transm Dis. 2008;35(9):827-833.

58. Weidner W, Schiefer H, Krauss H, Jantos C, Friedrick H, Altmannsberger M. Chronic prostatitis: A thorough search for etiologically involved microorganisms in 1,461 patients. Infection. 1991;19 Suppl 3:119-125.

59. Doble A, Thomas B, Walker M, Harris J, Witherow R, Taylor-Robinson D. The role of Chlamydia trachomatis in chronic abacterial prostatitis: A study using ultrasound guided biopsy. J Urol. 1989;141(2): 332-333.

60. Paavonen J, Eggert-Kruse W. Chlamydia trachomatis: Impact on human reproduction. Hum Reprod Update. 1999;5(5):433-447.

61. Eggert-Kruse W, Buhlinger-Gopfarth N, Rohr G, et al. Antibodies to Chlamydia trachomatis in semen and relationship with parameters of male fertility. Hum Reprod. 1996;11(7):1408-1417.

62. Mazzoli S, Cai T, Addonisio P, Bechi A, Mondaini N, Bartoletti R. Chlamydia trachomatis infection is related to poor semen quality in young prostatitis patients. Eur Urol. 2010;57(4):708-714.

63. Ouzounova-Raykova V, Ouzounova I, Mitov I. Chlamydia trachomatis infection as a problem among male partners of infertile couples. Andrologia. 2009;41(1):14-19.

64. Ness R, Markovic N, Carlson C, Coughlin M. Do men become infertile after having sexually transmitted urethritis? An epidemiologic examination. Fertil Steril. 1997;68(2):205-213.

65. Eggert-Kruse W, Rohr G, Demirakca T, et al. Chlamydial serology in 1303 asymptomatic subfertile couples. Hum Reprod. 1997;12(7): 1464-1475.

66. Fung M, Scott K, Kent C, et al. Chlamydia and gonorrhea re-infection among males: A systematic review of data to evaluate the need for re-testing. Sex Transm Infect. 2007;83(4):304-309.

67. Marazzo J, Martin D. Management of women with cervicitis. Clin Infect Dis. 2007;44 Suppl 3:S102-S110.

68. Brunham R, Paavonen J, Stevens C, et al. Mucopurulent cervicitis the ignored counterpart of urethritis in men. $N$ Engl J Med. 1984; 158(1):510-517.

69. Stamm W, Wagner K, Amsel R, et al. Causes of the acute urethral syndrome in women. N Engl J Med. 1980;303(8):409-415.

70. Wallin J, Thompson S, Zaidi A, Wong K. Urethritis in women attending an STD clinic. Br J Vener Dis. 1981;57(1):50-54.

71. Wolner-Hanssen P, Mardh P. In vitro tests of the adherence of Chlamydia trachomatis to human spermatozoa. Fertil Steril. 1984;42(1):102-107.

72. Friberg J, Confino E, Suarez M, Gleicher N. Chlamydia trachomatis attached to spermatozoa recovered from the peritoneal cavity of patients with salpingitis. J Reprod Med. 1987;32(2):120-122.

73. Zervomanolakis I, Ott H, Hadziomerovic D, et al. Physiology of upward transport in the human female genital tract. Ann NY Acad Sci. 2007;1101:1-20 
74. Paavonen J, Westrom L, Eschenbach D. Pelvic inflammatory disease. In: Holmes K, Sparling P, Mardh P-A, et al, editors. Sexually Transmitted Diseases. New York, NY: McGraw Hill; 2008.

75. Ijland M, Evans J, Dunselman G, Hoogland H. Subendometrial contractions in the nonpregnant uterus: An ultrasound study. Eur $J$ Obstet Gynecol Reprod Biol. 1996;70(1):23-24.

76. Ness R, Soper D, Holley R, et al. Effectiveness of inpatient and outpatient treatment strategies for women with pelvic inflammatory disease: Results from the PID Evaluation and Clinical Health (PEACH) randomized trial. Am J Obstet Gynecol. 2002;186(5):929-937.

77. Heinonen P, Meittinen A. Laporscopic study on the microbiology and severity of acute pelvic inflammatory disease. Eur J Obstet Gynecol Reprod Biol. 1994;57(2):85-89.

78. Ness R, Randall H, Richter $\mathrm{H}$, et al. Condom use and the risk of recurrent pelvic inflammatory disease, chronic pelvic pain, or infertility following an episode of pelvic inflammatory disease. Am J Public Health. 2004;94(8):1327-1329.

79. Haggerty C, Hillier S, Bass D, Ness R. Bacterial vaginosis and anaerobic bacteria are associated with endometritis. Clin Infect Dis. 2004;39(7):990-995.

80. Haggerty C, Ness R, Amortegui A, et al. Endometritis does not predict reproductive morbidity after pelvic inflammatory disease. Am J Obstet Gynecol. 2003;188(1):141-148.

81. Eckert L, Hawes S, Wolner-Hanssen P, et al. Endometritis: The clinicalpathologic syndrome. Am J Obstet Gynecol. 2002;186(4):690-695.

82. Weisenfeld H, Hillier S, Krohn M, et al. Lower genital tract infection and endometritis: Insight into subclinical pelvic inflammatory disease. Obstet Gynecol. 2002;100(3):456-463.

83. Ripa K, Sensson L, Treharne J, Westrom L, Mardh P. Chlamydia trachomatis infection in patients with laparoscopically verified acute salpingitis. Results of isolation and antibody determinations. Am J Obstet Gynecol. 1980;138(7 Pt 2):960-964.

84. Taylor-Robinson D, Stacey C, Jensen J, Thomas B, Munday P. Further observations, mainly serological, on a cohort of women with and without pelvic inflammatory disease. Int J STD AIDS. 2009;20(10): $712-718$.

85. Bevan C, Johal B, Mumtaz G, Ridgway G, Siddle N. Clinical, laparoscopic and microbiological findings in acute salpingitis: Report on a United Kingdom cohort. Br J Obstet Gynecol. 1995;102(5): 407-414.

86. Hook W III, Spitters C, Reichart C, Neumann T, Quinn T. Use of cell culture and rapid diagnostic assay for Chlamydia trachomatis screening. JAMA. 1994;272(11):867-870.

87. Geisler W, Wang C, Morrison S, Black C, Bandea C, Hook EW III. The natural history of untreated Chlamydia trachomatis infection in the interval between screening and returning for treatment. Sex Transm Dis. 2008;35(2):119-123.

88. Bachmann L, Richey C, Waites K, Schwebke J, Hook W III. Patterns of Chlamydia trachomatis testing and follow-up at a University Hospital Medical Center. Sex Transm Dis. 1999;26(9):496-509.

89. Morre S, van den Brule A, Rozendaal L, et al. The natural course of asymptomatic Chlamydia trachomatis infections: 45\% clearance and no development of clinical PID after one-year of follow-up. Int J STD AIDS. 2002;13 Suppl 2:12-18.

90. Rahm V, Belsheim J, Gleerup A, Gnarpe H, Rosen G. Asymptomatic carriage of Chlamydia trachomatis: A study of 109 teenage girls. Eur J Sex Transm Dis. 1986;3:91-94.

91. Bakken I, Ghaderi S. Incidence of pelvic inflammatory disease in a large cohort of women tested for Chlamydia trachomatis: A historical follow-up study. BMC Infect Dis. 2009;9:130.

92. Oakeshott P, Kerry S, Aghaizu A, et al. Randomised controlled trial of screening for Chlamydia trachomatis to prevent pelvic inflammatory disease: The POPI (Prevention Of Pelvic Infection) trial. BMJ. 2010; 340:c1642.

93. Ness R, Smith K, Chang C, Schisterman E, Bass D. Prediction of pelvic inflammatory disease among young, single, sexually active women. Sex Transm Dis. 2006;33(3):137-142.
94. Brunham R, Maclean I, Binns B, Peeling R. Chlamydia trachomatis: Its role in tubal infertility. J Infect Dis. 1985;152(6):1275-1282.

95. Miettinen A, Heinonen P, Teisala K, Hakkarainen K, Punnonen R. Serologic evidence for the role of Chlamydia trachomatis, Neisseria gonorrhoeae, and Mycoplasma hominis in the etiology of tubal factor infertility and ectopic pregnancy. Sex Transm Dis. 1990;17(1):10-14.

96. Toye B, Laferriere C, Claman P, Jessamine P, Peeling R. Association between antibody to the chlamydial heat shock protein and tubal infertility. J Infect Dis. 1993;168(5):1236-1240.

97. Tiitinen A, Surcel H, Halttunen M, et al. Chlamydia trachomatis and chlamydial heat shock protein 60 -specific antibody and cell-mediated responses predict tubal factor infertility. Hum Reprod. 2006;21(6): $1533-1538$.

98. Brunham R, Peeling R, MacLean I, Kosseim M, Paraskevas M. Chlamydia trachomatis-associated ectopic pregnancy: Serological and histological correlates. J Infect Dis. 1992;165(6):1076-1081.

99. Sziller I, Witkin S, Ziegert M, Csapo Z, Ujhazy A, Papp Z. Serological responses of patients with ectopic pregnancy to epitopes of the Chlamydia trachomatis $60 \mathrm{kDa}$ heat shock protein. Hum Reprod. 1998;13(4):1088-1093.

100. Safrin S, Schachter J, Dahrouge D, Sweet R. Long-term sequelae of acute pelvic inflammatory disease. A retrospective cohort study. Am J Obstet Gynecol. 1992;166(4):1300-1305.

101. Evans C, Das C, Kinghorn G. A retrospective study of recurrent chlamydia infection in men and women: Is there a role for targeted screening for those at risk? Int J STD AIDS. 2009;20(3):188-192.

102. Skjeldestad F, Marsico M, Sings H, Nordbo S, Storvold G. Incidence and risk factors for genital Chlamydia trachomatis infection: A 4-year prospective cohort study. Sex Transm Dis. 2009;36(5):273-279.

103. Kimani J, Maclean I, Bwayo J, et al. Risk factors for Chlamydia trachomatis pelvic inflammatory disease among sex workers in Nairobi, Kenya. J Infect Dis. 1996;173(6):1437-1444.

104. Ness R, Soper D, Richter H, et al. Chlamydia antibodies, chlamydia heat shock protein and adverse sequelae after pelvic inflammatory disease: The PID Evaluation and Clinical Health (PEACH) Study. Sex Transm Dis. 2008;35(2):129-135.

105. Low N, Bender N, Nartey L, Shang A, Stephenson J. Effectiveness of chlamydia screening: Systematic review. Int J Epidemiol. 2009;38(2): 435-448.

106. Howell M, Quinn T, Gaydos C. Screening for Chlamydia trachomatis in asymptomatic women attending family planning clinics. As cost-effectiveness analysis of three strategies. Ann Intern Med. 1998; 128(4):277-284

107. Welte R, Kretzschmar M, Leidl R, van den Hoek A, Jager J, Postma M. Cost-effectiveness of screening programs for Chlamydia trachomatis: A population-based dynamic approach. Sex Transm Dis. 2000; 27(9):518-529.

108. Goeree R, Jang D, Blackhouse G, et al. Cost-effectiveness of screening swab or urine specimens for Chlamydia trachomatis from young Canadian women in Ontario. Sex Transm Dis. 2001;28(12):701-709.

109. Hu D, Hook E, Goldie S. Screening for Chlamydia trachomatis in women 15 to 29 years of age: A cost effectiveness analysis. Ann Intern Med. 2004;141(7):501-513.

110. Land J, van Bergen J, Morre S, Postma M. Epidemiology of Chlamydia trachomatis infection in women and the cost-effectiveness of screening. Hum Reprod Update. 2010;16(2):189-204.

111. Van Valkengoed I, Morre S, van den Brule A, Meijer C, Bouter L, Boeke A. Overestimation of complication rates in evaluations of Chlamydia trachomatis screening programmes - implications for cost-effectiveness analysis. Int J Epidemiol. 2004;33(2):416-425.

112. Hu D, Hook E, Goldie S. The impact of natural history parameters on the cost-effectiveness of Chlamydia trachomatis screening strategies. Sex Transm Dis. 2006;33(7):428-436.

113. Roberts T, Robinson S, Barton P, et al. Cost effectiveness of home based population screening for Chlamydia trachomatis in the UK: Economic evaluation of chlamydia screening studies (ClaSS) project. BMJ. 2007;335(7614):291. 
114. Adams E, Turner K, Edmunds W. The cost effectiveness of opportunistic chlamydia screening in England. Sex Transm Infect. 2007;83(4):267-274.

115. Østergaard L, Anderson B, Olesen F, Møller J. Efficacy of home sampling for screening of Chlamydia trachomatis: Randomised study. BMJ. 1998;317(7150):26-27.

116. Herlitz C, Steel J. A decade of HIV/AIDS prevention in Sweden: Changes in attitudes associated with HIV and sexual risk behavior from 1987 to 1997. AIDS. 2000;14(7):881-890.

117. Burstein G, Zenilman J, Gaydos C, et al. Predictors of repeat Chlamydia trachomatis infections diagnosed by DNA amplification testing among inner city females. Sex Transm Infect. 2001;77(1):26-32.

118. Niccolai L, Hochberg A, Ethier K, Lewis J, Ickovics J. Burden of recurrent Chlamydia trachomatis infections in young women: Further uncovering the "hidden epidemic". Arch Pediatr Adolesc Med. 2007; 161(3):246-251.

119. Whittington W, Kent C, Kissinger P, et al. Determinants of persistent and recurrent Chlamydia trachomatis infection in young women: Results of a multicenter cohort study. Sex Transm Dis. 2001;28(2): 117-123.

120. Scholes D, Stergachis A, Heidrich F, Andrilla H, Holmes K, Stamm W. Prevention of pelvic inflammatory disease by screening for cervical chlamydial infection. N Engl J Med. 1996;334(21):1362-1366.

121. Østergaard L, Anderson B, Møller, Olesen F. Home sampling versus conventional swab sampling for screening of Chlamydia trachomatis in women: A cluster-randomized 1 year follow-up study. Clin Infect Dis. 2000;31(4):951-957.

122. Haggerty C, Peipert J, Weitsen S, et al. Predictors of chronic pelvic pain in an urban population of women with symptoms and signs of pelvic inflammatory disease. Sex Transm Dis. 2005;32(5):293-299.

123. Centers for Disease Control. Sexually transmitted diseases treatment guidelines. Morbid Mortal Wkly Rep. 2010;55:79-85.

124. Schachter J. Rifampin in chlamydial infections. Rev Infect Dis. 1983; 5 Suppl 3:S562-S564.

125. Schachter J, Stephens R. Biology of Chlamydia trachomatis. In: Homes K, Sparling P, Mardh P-A, et al, editors. Sexually Transmitted Diseases. New York, NY: McGraw Hill; 2008.

126. Lau C, Qureshi A. Azithromycin versus doxycycline for genital chlamydial infections: A meta-analysis of randomized clinical trials. Sex Transm Dis. 2002;29(9):497-502.
127. Pal S, Peterson E, de la Maza L. Vaccination with the Chlamydia trachomatis major outer membrane protein can elicit an immune response as protective as that resulting from inoculation with live bacteria. Infect Immun. 2005;73(12):8153-8160.

128. Pal S, Peterson E, Rappuoli R, Ratti G, de la Maza L. Immunization of the Chlamydia trachomatis major outer membrane protein, using adjuvants developed for human vaccines, can induce partial protection in a mouse model against genital challenge. Vaccine. 2006;24(6): $766-775$

129. Shaw J, Grund V, Durling L, Crane D, Caldwell H. Dendritic cells pulsed with a recombinant chlamydial major outer membrane protein antigen elicit a CD4(+) type 2 rather than type 1 immune response that is not protective. Infect Immun. 2002;70(3):1097-1105.

130. Pal S, Theodor I, Peterson E, de al Maza L. Immunization with the Chlamydia trachomatis mouse pneumonitis major outer membrane protein can elicit a protective immune response against a genital challenge. Infect Immun. 2001;69(10):6240-6247.

131. Zhang D, Yang X, Berry J, Shen C, McClarty G, Brunham R. DNA vaccination with the major outer-membrane protein gene induces acquired immunity to Chlamydia trachomatis (mouse pneumonitis) infection. J Infect Dis. 1997;176(4):1035-1040.

132. Wehrl W, Brinkman V, Jungblut P, Meyer T, Szczepek A. From the inside out - processing of the chlamydial autotransporter PmpD and its role in bacterial adhesion and activation of human host cells. Mol Microbiol. 2003;51(2):319-334.

133. Niessner A, Kaun C, Zorn G, et al. Polymorphic membrane protein (PMP) 20 and PMP 21 of Chlamydia pneumoniae induce proinflammatory mediators in human endothelial cells in vitro by activation of the nuclear factor-kB pathway. J Infect Dis. 2003;188(1): 108-113.

134. Crane D, Carlson J, Fischer E, et al. Chlamydia trachomatis polymorphic membrane protein $\mathrm{D}$ is a species-common pan-neutralizing antigen. Proc Natl Acad Sci U S A. 2006;103(6):1894-1899.

135. Tan C, Hsia R, Shou H, Carrasco J, Rank R, Bavoil P. Variable expression of surface-exposed polymorphic membrane proteins in in vitro-grown Chlamydia trachomatis. Cell Microbiol. 2010;12(2): 174-187.
Infection and Drug Resistance

\section{Publish your work in this journal}

Infection and Drug Resistance is an international, peer-reviewed openaccess journal that focuses on the optimal treatment of infection (bacterial, fungal and viral) and the development and institution of preventive strategies to minimize the development and spread of resistance. The journal is specifically concerned with the epidemiology of antibiotic

\section{Dovepress}

resistance and the mechanisms of resistance development and diffusion in both hospitals and the community. The manuscript management system is completely online and includes a very quick and fair peerreview system, which is all easy to use. Visit http://www.dovepress.com/ testimonials.php to read real quotes from published authors. 